\title{
Survival analysis in breast cancer using proteomic data from four independent datasets
}

RUNNING TITLE: Survival analysis using proteomic data

\author{
AUTHORS \\ Ágnes Ösz ${ }^{1,3}$, András Lánczky ${ }^{1}$, Balázs Győrffy ${ }^{1,2,3}$ \\ ${ }^{1}$ Semmelweis University Department of Bioinformatics, H-1094, Budapest, Hungary \\ ${ }^{2}$ Semmelweis University $2^{\text {nd }}$ Department of Pediatrics, H-1094, Budapest, Hungary \\ 3 TTK Momentum Cancer Biomarker Research Group, Institute of Enzymology, H-1117, \\ Budapest, Hungary
}

\section{CORRESPONDENCE}

Balázs Győrffy MD PhD

Semmelweis University Dept. of Bioinformatics

Tüzoltó u. 7-9, H-1094, Budapest, Hungary

gyorffy.balazs@med.semmelweis-univ.hu

\begin{abstract}
Breast cancer clinical treatment selection is based on the immunohistochemical determination of four proteins: ESR1, PGR, HER2, and MKI67. Our aim was to correlate immunohistochemical results to proteome-level technologies in measuring the expression of these markers. We also aimed to integrate available proteome-level breast cancer datasets to identify and validate new prognostic biomarker candidates.

We identified protein studies involving breast cancer patient cohorts with published survival and proteomic information. Immunohistochemistry and proteomic technologies were compared using the Mann-Whitney test. Receiver operating characteristics (ROC) curves were generated to validate discriminative power. Cox regression and Kaplan-Meier survival analysis were calculated to assess prognostic power. The false discovery rate was computed to correct for multiple hypothesis testing.

The complete database contains protein expression data and survival information from four independent cohorts for 1,229 breast cancer patients. In all four studies combined, a total of 7,342 unique proteins were identified, and 1,417 of these were identified in at least three
\end{abstract}


datasets. ESR1, PGR, HER2 protein expression levels determined by RPPA or LC-MS/MS methods showed a significant correlation with the levels determined by immunohistochemistry $(\mathrm{p}<0.0001)$. PGR and ESR1 levels showed a moderate correlation (correlation coefficient $=0.17, \mathrm{p}=0.0399$ ). A panel of candidate proteins, including apoptosisrelated proteins (BCL2,), adhesion markers (CDH1, CLDN3, CLDN7) and basal markers (cytokeratins), were validated as prognostic biomarkers. We expanded our established web tool to validate survival-associated biomarkers to include the proteomic datasets analyzed in this study (https://kmplot.com/analysis/).

Large proteomic studies now provide sufficient data enabling the validation and ranking of new protein biomarkers.

KEYWORDS: immunohistochemistry, mass spectrometry, RPPA, breast cancer molecular subtypes, Cox, Kaplan-Meier 


\section{INTRODUCTION}

Breast cancer is one of the most frequently diagnosed cancers and the leading cause of cancer-related death in women (1). Routine utilization of histopathological markers has led to better survival outcomes in personalized therapy, while multigenic genomic and transcriptomic analyses have further defined clinically meaningful molecular subtypes (2). Genomics provides the "blueprint" for cellular structure and functions, but due to its nature, it is always static, and the genome itself does not define the biological function. On the other hand, proteomics can show the physical structure of the cell, revealing a dynamic picture of active key functional elements. Proteomics can display the status of over 500,000 gene products defined by only approximately 30,000 genes. Overall, proteomics can provide a snapshot of the biological functions within a cancer cell. However, the availability of proteomic data derived from large patient cohorts is still limited.

Routine methods used for protein quantification include antibody-based techniques, such as immunohistochemistry (IHC) and reverse-phase protein array (RPPA), enzyme-linked immunosorbent assays (ELISA) and mass spectrometry (MS)-based technologies. ELISA invented in the 1970s is extensively used in laboratory practice for analyzing a small number of proteins, but its limitations in multiplexing requiring high developmental costs and wellcharacterized antibodies prevented its large-scale application (3). IHC is currently the gold standard method in routine pathological diagnosis, including the semiquantitative determination of ESR1, PGR and HER2 receptor status in breast tumors. Multiplexing of IHC is achieved in tissue microarrays, but even these achieve higher output by multiplexing the patient samples and not by multiplexing the proteins simultaneously evaluated. Nevertheless, tissue microarrays play a solid role in uncovering new biomarkers in cancer research (4). Although IHC is the most frequently used protein analysis method in oncology, it also has limits in the quantification and detection of activated proteins (5).

In contrast to antibody-based methods, the RPPA technique, introduced in 2001, immobilizes the whole protein lysate on a solid phase in multiple dots. A specific antibody solution is added to each array spot separately to achieve sensitive and simultaneous detection of proteins in small sample amounts (e.g., biopsy). RPPA requires well-specified antibodies, but it also makes it feasible to quantify the phosphorylation status of proteins and thus enables the characterization of entire pathways (6). 
Mass spectrometry (MS)-based technologies have rapidly advanced in recent years. In addition to speed, the second most prominent advantage of these methods is their ability to facilitate de novo identification and quantification of multiple proteins simultaneously. However, MS requires high initial cost, manual and time-consuming sample preparation, and an experienced technician to run the samples and interpret the data (7). Three major quantitative MS-based techniques have been developed: shotgun (or discovery), directed, and targeted proteomics. The shotgun method is based on the sequencing of peptides digested from the whole proteome and analyzing them via liquid chromatography and tandem mass spectrometry (LC-MS/MS) and automated database searching (8). Then, the protein quantity is calculated from the signal of detected peptides (ion intensity) or recorded number of MS/MS spectra (spectral counting). Protein abundance is normalized to the background proteome signal of measured samples (LFQ) or to an internal standard added to a labeled experiment $(9,10)$.

These methods enable comprehensive large-scale analysis of the human proteome. International initiatives have emerged to facilitate collaboration and data sharing. The Human Proteome Organization (HUPO, www.hupo.org) initiated in 2010 the Human Proteome Project (HPP) aiming for the determination of the human proteome using a standardized analytical pipeline (11). Major data repositories for MS-based protein datasets include the ProteomeXchange Consortium (http://www.proteomexchange.org), PRIDE (http://www.ebi.ac.uk/pride), and PeptideAtlas (http://www.peptideatlas.org) (12). The Human Protein Atlas portal (www.proteinatlas.org) provides antibody-based data of normal and cancerous tissues (13). The Clinical Proteomic Tumor Analysis Consortium (CPTAC, https://cptac-data-portal.georgetown.edu/cptacPublic) of the National Cancer Institute curates combined genomic and proteomic data of multiple tumor types (14). Finally, a side project of The Cancer Genome Atlas (TCGA) Project, The Cancer Proteome Atlas (TCPA, https://tcpaportal.org/tcpa/index.html) contains a large RPPA-based protein expression cohort (9).

Breast cancer is classified into four molecular subtypes, each having different molecular and prognostic characteristics. In the clinical routine, immunohistochemistry is used to measure the presence of estrogen receptor (ESR1), progesterone receptor (PGR), human epidermal growth factor receptor 2 (HER2) and the proliferation marker MKI67. Evaluation of these biomarkers is mandatory to assign patients into clinically effective treatment subtypes termed basal (receptor negative), luminal A (ESR1 and PGR positive and 
low MKI67), luminal B (ESR1 and PGR positive and high MKI67), and HER2-enriched (HER2 positive ESR1 negative) (15). Of note, additional markers, including androgen receptor (AR), epidermal growth factor receptor (EGFR) and cytokeratins (CK), have also been proposed for biomarker-based subtyping $(16,17)$.

Proteomic datasets comprise a large amount of protein-level data for each included specimen, and therefore, these datasets can provide an opportunity to validate existing prognostic biomarkers. In addition, by simultaneously analyzing multiple proteins in the same sample cohort, one can compare and rank new biomarker candidates. However, utilization of these sample cohorts is difficult due to limited/unavailable clinical data, ambiguous analysis pipelines, and discrepant gene annotations. Here, our first goal was to establish a breast cancer proteomic resource database by combining samples from multiple large independent studies. Then, we aimed to utilize this resource to validate and rank prognostic protein biomarkers in breast cancer.

\section{MATERIAL AND METHODS}

\section{Construction of the integrated protein database}

We searched for publications and datasets containing proteome and survival data for breast cancer patients in PubMed, The Cancer Proteome Atlas (TCPA) (9) and the ProteomeXchange Consortium (18) portals. The search terms "human", "breast", and "cancer" were used to identify eligible datasets. Only studies with available protein expression data generated by either mass spectrometry or RPPA, clinical survival information, and at least 50 cancer patients met our inclusion criteria. Four protein datasets met these conditions $(9,19-21)$. Due to the use of different platforms and analysis methods, it was not possible to merge the datasets into a single unified dataset. Therefore, each dataset was processed separately. In the analyses, the author-reported normalized expression data were used. Figure 1 summarizes the pipeline of data filtering.

\section{Protein annotation}

In each dataset, the protein annotation generated by the authors was the starting point and duplicated and non-annotated proteins were removed. In addition, UniProt IDs were used to identify gene symbols corresponding to the same genes. The final integrated table of all 
annotated proteins in the database, including the gene symbol, UniProt ID and TCPA antibody list, is provided as Supplemental Table 1.

\section{Validation of proteome-based protein level determination}

To determine how effective recent proteomic technologies are in assessing the actual protein levels, we compared proteome-based results to conventional immunohistochemistry results. Such data were available in multiple data sets for genes with therapeutic importance, including ESR1, PGR, HER2 and MKI67. All validation analyses were performed in each of the four cohorts separately. In the case of MKI67, we also compared the expression between normal and tumor tissue, as this was available in one dataset.

\section{Correlation between protein biomarker candidates and survival}

We performed a PubMed search to identify previously published biomarker candidates related to survival using the search terms "breast cancer", "protein", "cohort", "marker", and "survival". Publications describing cell lines, other tumor types, those not investigating a tumor tissue, and studies with fewer than 100 patients were excluded. After these restrictions, 53 publications remained. In addition, we examined ten additional publications describing breast cancer guidelines. In all 63 publications, a total of 91 proteins were described, 57 of which were present in our database. This list includes FDA-approved biomarkers, growth factor receptors, immune receptor ligands, basal and adhesion markers (cytokeratins, cadherins, and claudins), stem cell markers, and apoptotic markers (Supplemental Table 2). We analyzed all 57 protein biomarkers used in breast cancer diagnostics for their prognostic power. The validation of the markers was performed separately in each dataset using overall survival and relapse-free survival time.

\section{Statistical analyses}

Differential expression was evaluated using the Mann-Whitney test. Receiver operating characteristics (ROC) were computed to measure sensitivity and specificity and to validate discriminative power. ROC was also utilized to determine the optimal cutoff values to define cohorts based on the expression of the investigated proteins. Spearman rank correlation coefficients were calculated to assess the correlation of continuous variables. To measure the association between protein expression and survival length, the patients were grouped into high and low expression groups based on the expression of the selected protein. Then, the two groups were compared by Cox proportional hazards regression, and hazard 
ratios (HRs), 95\% confidence intervals (CIs) and log-rank p values were calculated. Finally, for a selected set of markers, Kaplan-Meier plots were generated to display the different survival characteristics of the two cohorts. For cutoff values, each potential threshold was analyzed between the lower and upper quartiles, and the false discovery rate (FDR) was computed to correct for multiple hypothesis testing. The results were accepted as significant when $\mathrm{p}<0.05$ and $\mathrm{FDR}<0.2$.

\section{Survival analysis web tool}

We previously created an online analysis platform utilizing transcriptome-level mRNA expression (22) and miRNA expression (23) data together with clinical, follow-up, and pathological data to assess the correlation between gene expression and survival in breast cancer. Here, we have established a new subsystem of this analysis platform. The complete proteomic database is now integrated into this system, and new biomarker candidates, as well as each biomarker assessed here, can be rapidly evaluated using the registration-free analysis site. In the tool, selection of the proteins can be performed using the gene symbol, the UniProt ID or the RPPA antibody name (https://kmplot.com/analysis/).

\section{RESULTS}

\section{Integrated breast cancer protein database}

Altogether, 140 datasets were identified, of which 30 studies had at least some clinical information for the included patients. We listed all these datasets in Table 1. After exclusion of those without survival data and other ineligible studies, four independent projects remained. These four datasets comprise 1,229 specimens and 7,342 unique proteins. The entire set of patients included 1,064 overall survival (OS) and 998 relapse-free survival (RFS) records. Two datasets had either only overall (Tang 2018) or relapse-free survival data (DeMarchi 2015). Median OS and RFS times varied between 27.6-96.5 months and 9.6-85.5 months, respectively. The mean age of the patients was $57.7 \pm 13.6$ years. In line with our expectations, estrogen receptor-positive (ESR1+) patients represented approximately $67 \%$ of all samples, and almost half of the patients had nodal involvement (46\%). Of note, the Liu 2014 dataset included triple negative breast cancer (TNBC), lymph node negative and treatment naive patients only. In the other studies, hormone therapy, primarily tamoxifen, was 
applied (59\%). Table 2 contains detailed clinical parameters for each included dataset used, and Figure 2 shows selected clinical characteristics for these datasets.

The dataset generated using RPPA contains most of the patients $(n=873)$ but least of the proteins $(n=224)$. The other three datasets have combined $>7000$ protein records measured by LC-MS/MS technology. Figure 3A shows the proportions of detected proteins in each dataset combination. Only 39 proteins were measured in all datasets, while 1,356 overlapping proteins were evaluated in the three LC-MS/MS studies. A total of 4,731 proteins were detected in only one study, and most of them came from the Tang 2018 cohort $(n=4,225)$. When mapping the measured proteins to cellular locations, the majority of proteins originated from the cytoplasm (36.3\%), nucleus (32.2\%) and cytosol (27.6\%) (Figure 3B and 3C). Supplemental Table 1 includes all proteins.

\section{Evaluation of routine diagnostic biomarkers}

ESR1, PGR and HER2 protein expression levels determined by RPPA were compared to IHC-based receptor status and the results revealed that protein expression and receptor status were highly significantly correlated with one another $(\mathrm{p}<0.0001)$ (see Figure 4A-C). When running ROC analysis using RPPA-based continuous HER2 levels, the proteomic measurements delivered a substantial area under the ROC curve (AUC) of $0.74(\mathrm{p}=1.9 \mathrm{e}-20)$. ESR1 protein expression determined by LC-MS/MS also delivered a reliable correlation to IHC results $(\mathrm{p}=0.0423)$ (Figure 4D). The AUC value for ESR1 levels determined by LCMS/MS was $0.61(\mathrm{p}=0.03)$.

The Tang et al dataset included paired normal and tumor samples for 53 patients. When comparing the expression of the proliferation marker MKI67 between the normal and cancer samples, the tumor samples had significantly higher expression (fold change $=2.22$, $\mathrm{p}=0.0001$ ) (Figure 4E).

Finally, we also assessed the correlation between ESR1 and the ESR1-regulated gene PGR. In this analysis, we uncovered a moderate correlation between ESR1 and PGR protein expression levels, as determined by LC-MS/MS (correlation coefficient $=0.17, p=0.0399$, Figure 4F). Unfortunately, due to the limited availability of simultaneously collected data, it was not possible to analyze all possible clinical scenarios and to model molecular subtype determination based on proteomic datasets.

\section{Proteins with significant prognostic power}


We assessed the link between survival and the expression of 63 proteins and their phosphorylated forms to validate their prognostic relevance in breast cancer (Supplemental Table 2). The expression of 33 of 63 proteins had a significant correlation with patient outcome. Twelve proteins associated with OS only, nine proteins associated with RFS only, and twelve proteins (PGR, CDH1, BCL2, NDRG1, CTNNB1, APOD, PARP1, RBM3 and four cytokeratins: KRT18, KRT5, KRT6B, KRT17) were prognostic for both RFS and OS. Of these, three proteins (KRT18, APOD and CDH1) and four proteins (PGR, CDH1, CTNNB1, and BCL2) were confirmed to be related to OS and RFS, respectively, in at least two independent datasets. The results of the survival analysis for each of these proteins in terms of OS and RFS are displayed in Table $\mathbf{3 A}$ and $\mathbf{3 B}$, respectively.

A better overall survival outcome was associated with higher expression of E-cadherin $(\mathrm{HR}=0.21,95 \% \mathrm{CI}=0.08-0.6, \mathrm{p}=0.0013)$ and the apoptosis regulator protein $\mathrm{BCL} 2(\mathrm{HR}=0.6$, 95\% $\mathrm{CI}=0.39-0.81, \mathrm{p}=0.0017)$. Higher BCL2 was also strongly related to longer relapse-free survival $(\mathrm{HR}=0.4,95 \% \mathrm{CI}=0.27-0.61, \mathrm{p}=9.5 \mathrm{e}-06)$. While we also validated the prognostic value of the expression level of tyrosine 1248-phosphorylated HER-2 (HER2_pY1248) $(\mathrm{HR}=1.63,95 \% \mathrm{CI}=1.13-2.36, \mathrm{p}=0.0079)$ using RPPA data, the expression level of nonphosphorylated HER-2 did not have a significant correlation with survival in any of the included datasets. Both estrogen receptor and progesterone receptor were linked to improved relapse-free survival $\quad(\mathrm{HR}=0.3, \quad 95 \% \mathrm{CI}=0.19-0.49, \quad \mathrm{p}=1.9 \mathrm{e}-07 \quad$ and $\mathrm{HR}=0.4$, $95 \% \mathrm{CI}=0.26-0.69, \mathrm{p}=0.0004$, respectively). Kaplan-Meier curves for these proteins are shown in Figure 5A-F.

\section{DISCUSSION}

A major advance of proteomic technologies lies in their ability to simultaneously measure multiple biomarkers from a single clinical specimen. Here, we collected four independent breast cancer proteomic cohorts and validated established and new biomarker candidates.

Despite the quantitative and multiplexing limitations of immunohistochemical analysis, in clinical practice, it is still the gold standard. We compared the efficiency of various proteomic techniques to determine routinely measured breast cancer biomarkers, including ESR1, PGR, HER2, and MKI67. In this analysis, both the RPPA and LC-MS/MS method results were highly correlated with IHC results and thus can be utilized to determine 
receptor status in breast cancer patients. Unfortunately, we did not have all markers for the same patients, and the results achieved for individual genes can only suggest that proteomic technologies will also be capable of performing molecular stratification in the future, enabling the discrimination of breast cancer subtypes.

Estrogen receptor is a pioneer cancer biomarker, and classifying breast tumors based on hormone receptor status has been utilized in routine clinical practice for over four decades (24). ESR1 positivity and PGR positivity are associated with better survival outcomes than negative ESR1/PGR status. In addition to clinicopathological prognostication, the main medical application of these receptors is selecting patients for endocrine therapy (25).

MKI67 is a protein not expressed in G0 phase, and thus, it is a perfect marker for determining the proportion of dividing cells. MKI67 expression is correlated with outcome, and high MKI67 expression is associated with poor prognosis, which has been validated in a meta-analysis involving over 64 thousand breast cancer patients (26). Immunohistochemical staining of MKI67 alone can also pinpoint low-risk breast cancers with the same reliability as genomic markers (27).

Evaluation of HER2 (ERBB2, neu) status has also been routinely used in breast cancer molecular diagnostics since the end of the 1990s. Analysis of large cohorts of patients found that HER2 overexpression is associated with unfavorable prognosis and poor response to chemotherapy (28). The clinical introduction of anti-HER2 therapies (i.e., trastuzumab, pertuzumab) in combination with chemotherapy in patients who have HER2-positive cancer results in exceptional survival advantages. As a result, HER2-positive patients have a better outlook than HER2-negative patients (29). Today, tumors with even 1\% positivity are eligible for anti-HER2 therapy (30).

Triple-negative breast cancer (TNBC) is diagnosed in cases where tumors are negative for ESR1, PGR, and HER2. In these breast tumors, the immunohistochemical measurement of basal markers (cytokeratin 5/6, EGFR), claudins (CLD3/4/7), cadherins (CDH1, CDH3), stem cell markers (CD44/CD24, ALDH1), apoptosis markers (BCL2, TP53), a transcription marker (YB-1) and urokinase-type plasminogen activator (uPA)/plasminogen activator inhibitor-1 (PAI-1) have also been suggested for advanced stratification $(16,17,31,32)$.

We assessed the prognostic power of a selected set of proteins, including ESR1, PGR, HER2, cytokeratins, claudins, E-cadherin (33) and EGFR, in the datasets included in the present study. Overall, we uncovered that 33 proteins had a significant correlation with 
prognosis. In the case of FDA-approved protein biomarkers, the expression of estrogen and progesterone receptors is correlated with favorable relapse-free survival. High expression levels of phosphorylated HER2 protein measured by RPPA were linked with worse overall survival than low expression levels; these findings are in line with the previous study by Hayashi et al. on the same protein (34).

High expression of the antiapoptotic Bcl-2 and the adhesion marker E-cadherin was related to longer relapse-free survival than low expression in at least two independent datasets. Bcl-2 overexpression was revealed in other cancers and was linked to cancer initiation and progression, and higher expression positively correlated with favorable patient outcomes in hormone receptor-positive breast tumors $(35,36)$. Loss of E-cadherin expression is frequently represented in invasive lobular breast carcinoma, which is three times more likely to metastasize (37).

Interestingly, some of the genes, including PGR and E-cadherin, display inverse correlations with survival when assessing the link to survival in different patient cohorts. Here, we have to mention some limitations of our analysis that might lie behind these discrepancies. A major constraint is that only $20 \%$ of the proteins were determined in at least three platforms. This means that the evaluation of further databases will be needed to perform a comprehensive validation of all potential biomarker candidates. Another shortcoming of the investigated datasets is the rather low proportion of events (in the case of the TCGA dataset) and the short follow-up time (DeMarchi dataset). A future large-scale proteomic database with long follow-up and uniform protein level determination using a single method could provide more reliable data for a similar analysis.

In summary, we successfully integrated four distinct breast cancer proteomic datasets containing tumor and normal samples. A significant correlation was observed between marker levels detected by proteomic technologies and those detected by immunohistochemistry results. We validated prognostic and predictive breast cancer biomarkers and compared the efficiency of different proteome analysis techniques. The entire database is integrated into our online tool, providing an opportunity to validate our findings and to identify and rank new survival-associated biomarker candidates using multiple independent cohorts of breast cancer. 


\section{AUTHOR CONTRIBUTIONS}

Concept and design: BG; Database setup: OA, BG; Analysis of data: OA, BG, AL; Data interpretation: OA, BG; Draft manuscript: OA, BG. All authors provided final approval of the manuscript.

\section{CONFLICT OF INTEREST}

The authors declare no conflicts of interest.

\section{ACKNOWLEDGEMENTS AND FUNDINGS}

The study was supported by the 2018-2.1.17-TET-KR-00001, 2018-1.3.1-VKE-201800032 and KH-129581 grants of the National Research, Development and Innovation Office, Hungary. The use of the computational infrastructure of Pázmány Péter University, provided within the National Bionics Program, is gratefully acknowledged. The authors acknowledge the support of ELIXIR Hungary (www.elixir-hungary.org).

\section{DATA AVAILABILITY STATEMENT}

Data sharing is not applicable to this article as no new data were created or analyzed in this study, however, we expanded our established web tool to validate survival-associated biomarkers to include the proteomic datasets analyzed in this study

(https://kmplot.com/analysis/). 


\section{REFERENCES}

1. Bray F, Ferlay J, Soerjomataram I, Siegel RL, Torre LA, Jemal A. Global cancer statistics 2018: GLOBOCAN estimates of incidence and mortality world wide for 36 cancers in 185 countries. CA: a cancer journal for clinicians. 2018;68(6):394-424.

2. Gyorffy B, Hatzis C, Sanft T, Hofstatter E, Aktas B, Pusztai L. Multigene prognostic tests in breast cancer: past, present, future. Breast cancer research : BCR. 2015;17:11.

3. Solier C, Langen H. Antibody-based proteomics and biomarker research - current status and limitations. Proteomics. 2014;14(6):774-83.

4. Camp RL, Neumeister V, Rimm DL. A decade of tissue microarrays: progress in the discovery and validation of cancer biomarkers. Journal of clinical oncology : official journal of the American Society of Clinical Oncology. 2008;26(34):5630-7.

5. Boellner S, Becker KF. Reverse Phase Protein Arrays-Quantitative Assessment of Multiple Biomarkers in Biopsies for Clinical Use. Microarrays. 2015;4(2):98-114.

6. Malinowsky K, Wolff C, Schott C, Becker KF. Characterization of signalling pathways by reverse phase protein arrays. Methods in molecular biology. 2013;1049:285-99.

7. Chung L, Moore K, Phillips L, Boyle FM, Marsh DJ, Baxter RC. Novel serum protein biomarker panel revealed by mass spectrometry and its prognostic value in breast cancer. Breast cancer research : BCR. 2014;16(3):R63.

8. Rodriguez-Suarez E, Whetton AD. The application of quantification techniques in proteomics for biomedical research. Mass spectrometry reviews. 2013;32(1):1-26.

9. Li J, Lu YL, Akbani R, Ju ZL, Roebuck PL, Liu WB, et al. TCPA: a resource for cancer functional proteomics data. Nat Methods. 2013;10(11):1046-7.

10. Sap KA, Demmers JAA. Labeling Methods in Mass Spectrometry Based Quantitative Proteomics. Integrative Proteomics. 2012:111-32.

11. Omenn GS, Lane L, Overall CM, Corrales FJ, Schwenk JM, Paik YK, et al. Progress on Identifying and Characterizing the Human Proteome: 2018 Metrics from the HUPO Human Proteome Project. Journal of proteome research. 2018;17(12):4031-41.

12. Deutsch EW, Csordas A, Sun Z, Jarnuczak A, Perez-Riverol Y, Ternent T, et al. The ProteomeXchange consortium in 2017: supporting the cultural change in proteomics public data deposition. Nucleic acids research. 2017;45(D1):D1100-D6.

13. Uhlen M, Fagerberg L, Hallstrom BM, Lindskog C, Oksvold P, Mardinoglu A, et al. Proteomics. Tissue-based map of the human proteome. Science. 2015;347(6220):1260419.

14. Rivers RC, Kinsinger C, Boja ES, Hiltke T, Mesri M, Rodriguez H. Linking cancer genome to proteome: NCI's investment into proteogenomics. Proteomics. 2014;14(23-24):2633-6.

15. Vasconcelos I, Hussainzada A, Berger S, Fietze E, Linke J, Siedentopf F, et al. The St. Gallen surrogate classification for breast cancer subtypes successfully predicts tumor presenting features, nodal involvement, recurrence patterns and disease free survival. Breast. 2016;29:181-5.

16. Portier BP, Gruver AM, Huba MA, Minca EC, Cheah AL, Wang Z, et al. From morphologic to molecular: established and emerging molecular diagnostics for breast carcinoma. New biotechnology. 2012;29(6):665-81.

17. Mueller C, Haymond A, Davis JB, Williams A, Espina V. Protein biomarkers for subtyping breast cancer and implications for future research. Expert review of proteomics. 2018;15(2):131-52.

18. Vizcaino JA, Deutsch EW, Wang R, Csordas A, Reisinger F, Rios D, et al. ProteomeXchange provides globally coordinated proteomics data submission and dissemination. Nature biotechnology. 2014;32(3):223-6.

19. Liu NQ, Stingl C, Look MP, Smid M, Braakman RB, De Marchi T, et al. Comparative proteome analysis revealing an 11-protein signature for aggressive triple-negative breast cancer. Journal of the National Cancer Institute. 2014;106(2):djt376.

20. De Marchi T, Liu NQ, Stingl C, Timmermans MA, Smid M, Look MP, et al. 4-protein signature predicting tamoxifen treatment outcome in recurrent breast cancer. Molecular oncology. 2016;10(1):24-39.

21. Tang W, Zhou M, Dorsey TH, Prieto DA, Wang XW, Ruppin E, et al. Integrated proteotranscriptomics of breast cancer reveals globally increased protein-mRNA concordance associated with subtypes and survival. Genome medicine. 2018;10(1):94. 
22. Gyorffy B, Lanczky A, Eklund AC, Denkert C, Budczies J, Li Q, et al. An online survival analysis tool to rapidly assess the effect of 22,277 genes on breast cancer prognosis using microarray data of 1,809 patients. Breast cancer research and treatment. 2010;123(3):725-31.

23. Lanczky A, Nagy A, Bottai G, Munkacsy G, Szabo A, Santarpia L, et al. miRpower: a webtool to validate survival-associated miRNAs utilizing expression data from 2178 breast cancer patients. Breast cancer research and treatment. 2016;160(3):439-46.

24. Osborne CK, Yochmowitz MG, Knight WA, 3rd, McGuire WL. The value of estrogen and progesterone receptors in the treatment of breast cancer. Cancer. 1980;46(12 Suppl):2884-8.

25. Hammond ME, Hayes DF, Dowsett M, Allred DC, Hagerty KL, Badve S, et al. American Society of Clinical Oncology/College of American Pathologists guideline recommendations for immunohistochemical testing of estrogen and progesterone receptors in breast cancer (unabridged version). Archives of pathology \& laboratory medicine. 2010;134(7):e48-72.

26. Petrelli F, Viale G, Cabiddu M, Barni S. Prognostic value of different cut-off levels of Ki-67 in breast cancer: a systematic review and meta-analysis of 64,196 patients. Breast cancer research and treatment. 2015;153(3):477-91.

27. Iwamoto T, Katagiri T, Niikura N, Miyoshi Y, Kochi M, Nogami T, et al. Immunohistochemical Ki67 after short-term hormone therapy identifies low-risk breast cancers as reliably as genomic markers. Oncotarget. 2017;8(16):26122-8.

28. Slamon DJ, Clark GM, Wong SG, Levin WJ, Ullrich A, McGuire WL. Human breast cancer: correlation of relapse and survival with amplification of the HER-2/neu oncogene. Science. 1987;235(4785):177-82.

29. Ross JS, Slodkowska EA, Symmans WF, Pusztai L, Ravdin PM, Hortobagyi GN. The HER-2 receptor and breast cancer: ten years of targeted anti-HER-2 therapy and personalized medicine. The oncologist. 2009;14(4):320-68.

30. Wolff AC, Hammond MEH, Allison KH, Harvey BE, Mangu PB, Bartlett JMS, et al. Human Epidermal Growth Factor Receptor 2 Testing in Breast Cancer: American Society of Clinical Oncology/College of American Pathologists Clinical Practice Guideline Focused Update. Journal of clinical oncology : official journal of the American Society of Clinical Oncology. 2018;36(20):2105-

22.

31. Blows FM, Driver KE, Schmidt MK, Broeks A, van Leeuwen FE, Wesseling J, et al.

Subtyping of breast cancer by immunohistochemistry to investigate a relationship between subtype and short and long term survival: a collaborative analysis of data for 10,159 cases from 12 studies.

PLoS medicine. 2010;7(5):e1000279.

32. Norum JH, Andersen K, Sorlie T. Lessons learned from the intrinsic subtypes of breast cancer in the quest for precision therapy. The British journal of surgery. 2014;101(8):925-38.

33. Szasz AM, Nemeth Z, Gyorffy B, Micsinai M, Krenacs T, Baranyai Z, et al. Identification of a claudin-4 and E-cadherin score to predict prognosis in breast cancer. Cancer science.

2011;102(12):2248-54.

34. Hayashi N, Iwamoto T, Gonzalez-Angulo AM, Ferrer-Lozano J, Lluch A, Niikura N, et al. Prognostic impact of phosphorylated HER-2 in HER-2+ primary breast cancer. The oncologist. 2011;16(7):956-65.

35. Dawson SJ, Makretsov N, Blows FM, Driver KE, Provenzano E, Le Quesne J, et al. BCL2 in breast cancer: a favourable prognostic marker across molecular subtypes and independent of adjuvant therapy received. British journal of cancer. 2010;103(5):668-75.

36. Honma N, Horii R, Ito Y, Saji S, Younes M, Iwase T, et al. Differences in clinical importance of Bcl-2 in breast cancer according to hormone receptors status or adjuvant endocrine therapy. BMC cancer. 2015;15:698.

37. Michaut M, Chin SF, Majewski I, Severson TM, Bismeijer T, de Koning L, et al. Integration of genomic, transcriptomic and proteomic data identifies two biologically distinct subtypes of invasive lobular breast cancer. Scientific reports. 2016;6:18517.

38. Cancer Genome Atlas N. Comprehensive molecular portraits of human breast tumours. Nature. 2012;490(7418):61-70. 


\section{FIGURES}

Figure 1. Data acquisition workflow, the number of samples and unique proteins in each included dataset.

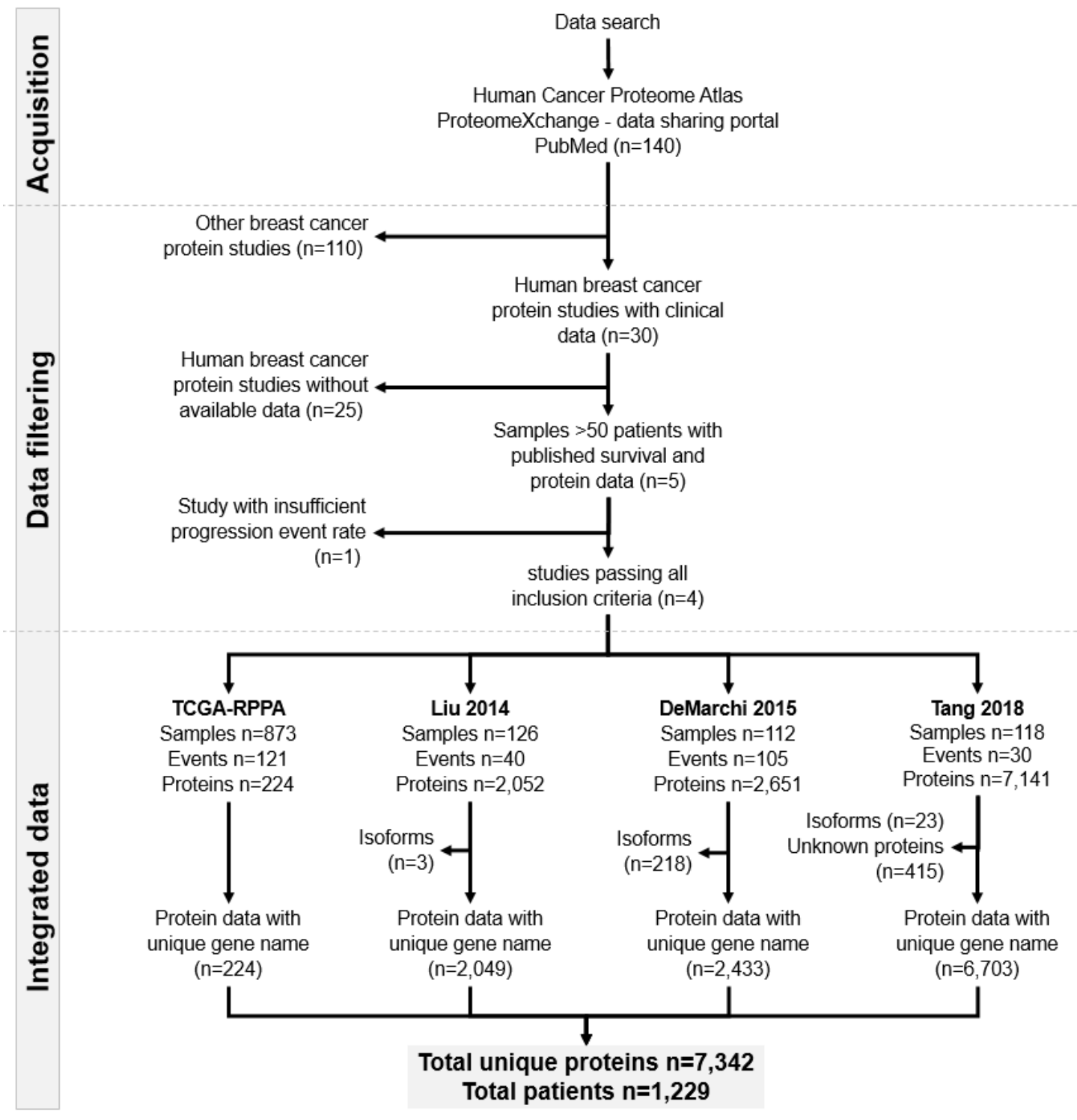


medRxiv preprint doi: https://doi.org/10.1101/2020.12.03.20242065; this version posted December 4, 2020. The copyright holder for this preprint (which was not certified by peer review) is the author/funder, who has granted medRxiv a license to display the preprint in perpetuity.

It is made available under a CC-BY-NC 4.0 International license.

Figure 2. Clinical characteristics of the breast cancer patients used in this study. A) Availability of clinical data in the included cohorts; B) the proportion of patients treated with radiation, hormones or chemotherapy. C) Percentage of patients by nodal status in each dataset; D)-E) the proportion of patients by receptor status for ESR1, PGR and HER2 in each dataset; F) the distribution of stage and grade; G) the mean age of patients; and $\mathbf{H}$ ) the mean follow-up time in each dataset.

A)

\begin{tabular}{|c|c|c|c|c|c|c|c|}
\hline & $\begin{array}{l}\frac{\infty}{ \pm} \\
\frac{\pi}{0} \\
\frac{\pi}{\infty} \\
\frac{\pi}{0} \\
\frac{0}{2}\end{array}$ & 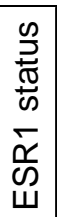 & 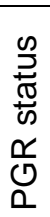 & 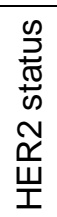 & $\begin{array}{l}\stackrel{0}{\mathscr{D}} \\
\text { ஸे }\end{array}$ & $\frac{\mathbb{0}}{\frac{\pi}{0}}$ & 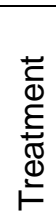 \\
\hline TCGA-RPPA & + & + & + & + & + & - & + \\
\hline Liu 2014 & + & + & + & + & - & + & + \\
\hline DeMarchi 2015 & + & + & - & - & - & - & + \\
\hline Tang 2018 & + & + & - & - & + & + & - \\
\hline
\end{tabular}

C)

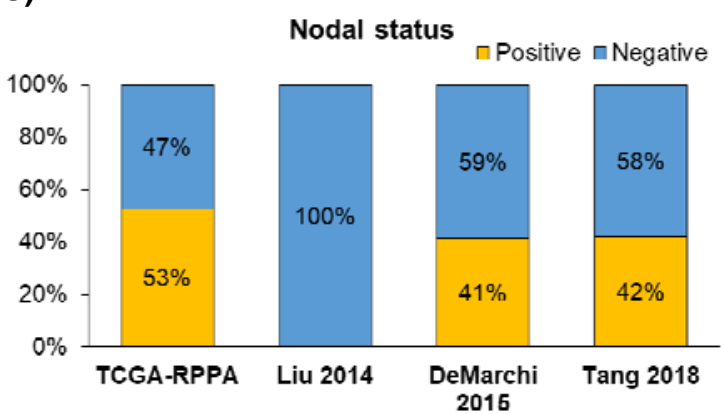

E)

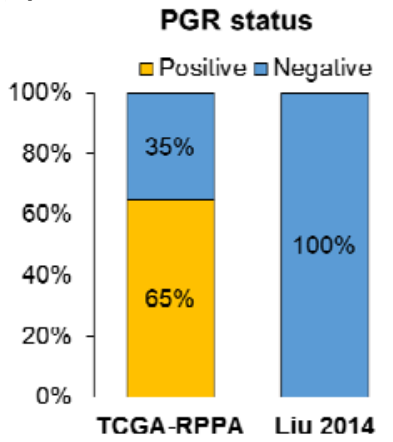

G)
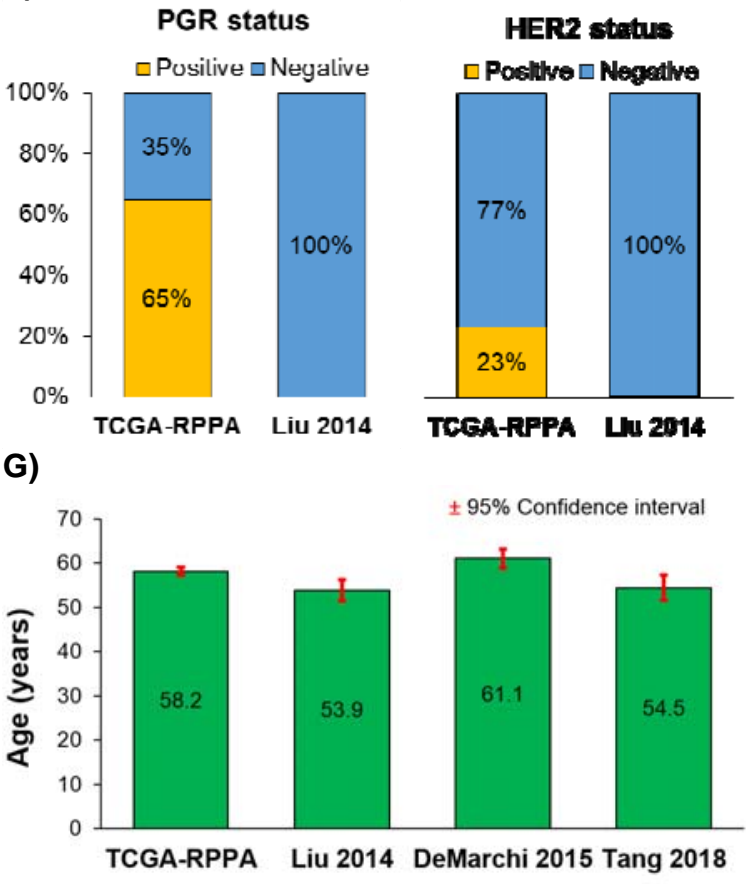

B)

TCGA-RPPA

Hormone

Chemo- Radiaton therapy therapy therapy
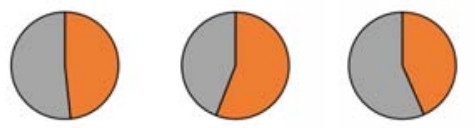

Liu 2014
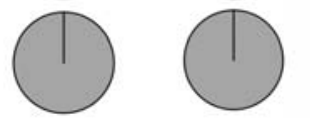

neated

घuntreated

DeMarchi 2015

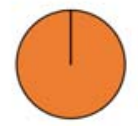

D)

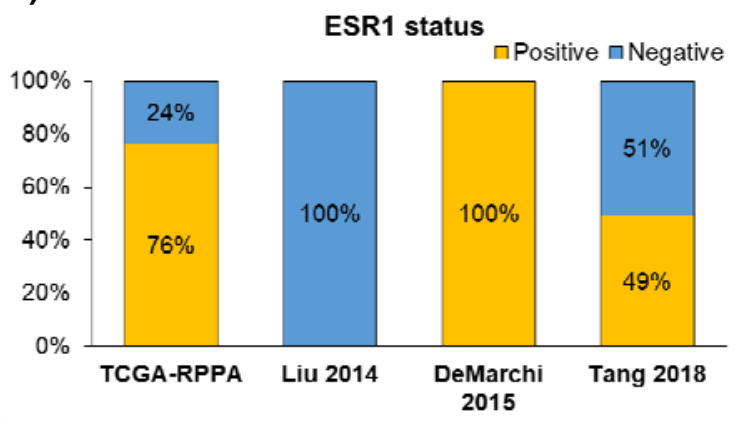

F)
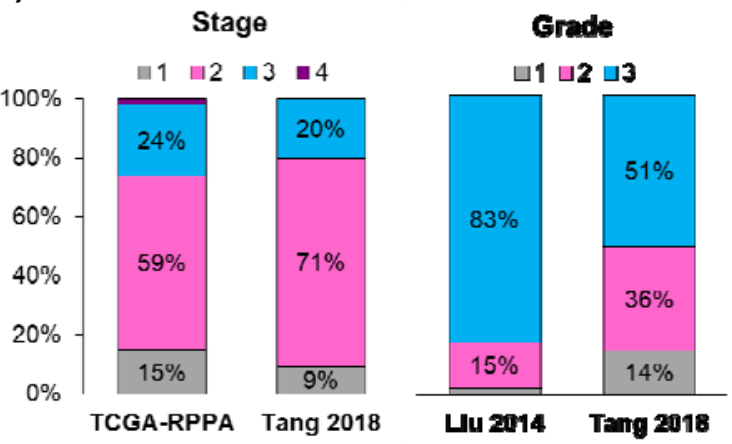

H)

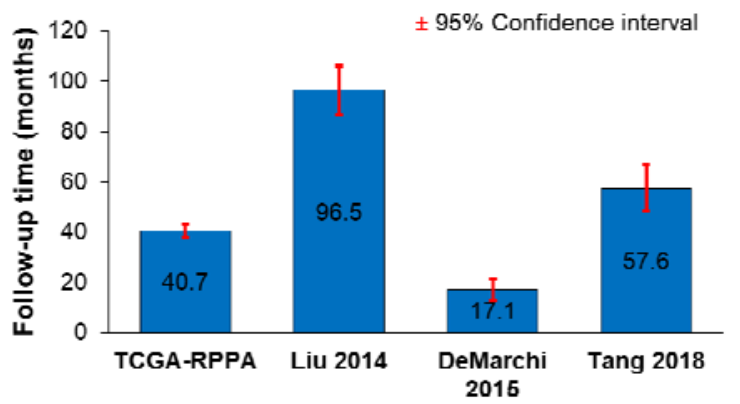


medRxiv preprint doi: https://doi.org/10.1101/2020.12.03.20242065; this version posted December 4, 2020. The copyright holder for this preprint (which was not certified by peer review) is the author/funder, who has granted medRxiv a license to display the preprint in perpetuity.

It is made available under a CC-BY-NC 4.0 International license.

Figure 3. Proteins measured in multiple studies and their cellular localizations. A) Number of proteins represented in one, two, three, or four datasets, B) proportion of proteins present in various cellular components, and $\mathbf{C}$ ) graphical representation of cellular origin of the analyzed proteins, where font size is relative to the proportion of proteins from that compartment.

A)

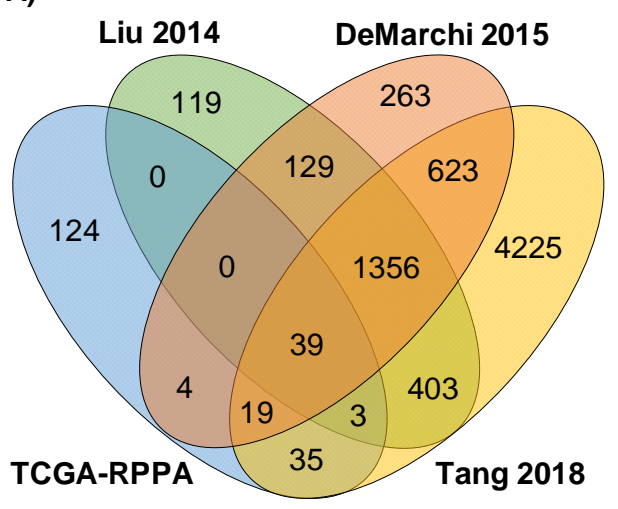

\begin{tabular}{l|c|c|c|} 
B) Location & GO ID & $\%$ & P value \\
\hline Cytoplasm & GO:0005737 & 36.3 & $4 \mathrm{E}-104$ \\
\hline Nucleus & GO:0005634 & 32.2 & $2 \mathrm{E}-21$ \\
\hline Cytosol & GO:0005829 & 27.6 & $1 \mathrm{E}-179$ \\
\hline Exosome & GO:0070062 & 25.6 & $5 \mathrm{E}-231$ \\
\hline Nucleoplasm & GO:0005654 & 21.0 & $6 \mathrm{E}-82$ \\
\hline Membrane & GO:0016020 & 18.8 & $1 \mathrm{E}-128$ \\
\hline Mitochondrion & GO:0005739 & 10.3 & $3 \mathrm{E}-44$ \\
\hline Extracellular space & GO:0005615 & 7.5 & $5 \mathrm{E}-02$ \\
\hline Nucleolus & GO:0005730 & 6.8 & $6 \mathrm{E}-33$ \\
\hline Golgi apparatus & GO:0005794 & 5.9 & $1 \mathrm{E}-12$ \\
\hline Endoplasmic reticulum & GO:0005783 & 5.6 & $2 \mathrm{E}-11$ \\
\hline Endoplasmic reticulum membrane & GO:0005789 & 5.5 & $1 \mathrm{E}-07$ \\
\hline Perinuclear region of cytoplasm & GO:0048471 & 5.0 & $1 \mathrm{E}-25$ \\
\hline
\end{tabular}

C)

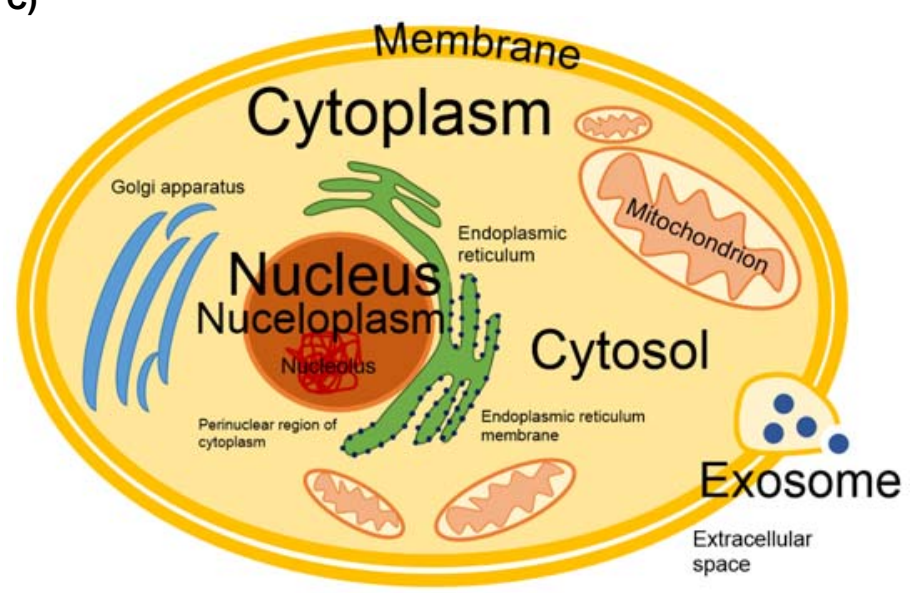


Figure 4. Validation of proteome-based molecular biomarker determination by comparing the results to those achieved by IHC-based receptor status determination. A)-C) ESR1, PGR, HER2 protein expression results determined by RPPA showed a significant correlation with IHC results. D) The correlation between ESR1 status by IHC and ESR1 protein expression levels measured by LC-MS/MS. E) MKI67 levels measured by LC-MS/MS showed higher expression in tumors than in normal samples in the Tang 2018 dataset $(n=53)$. F) Correlation between ESR1 and PGR protein expression levels in LC-MS/MS data.

A

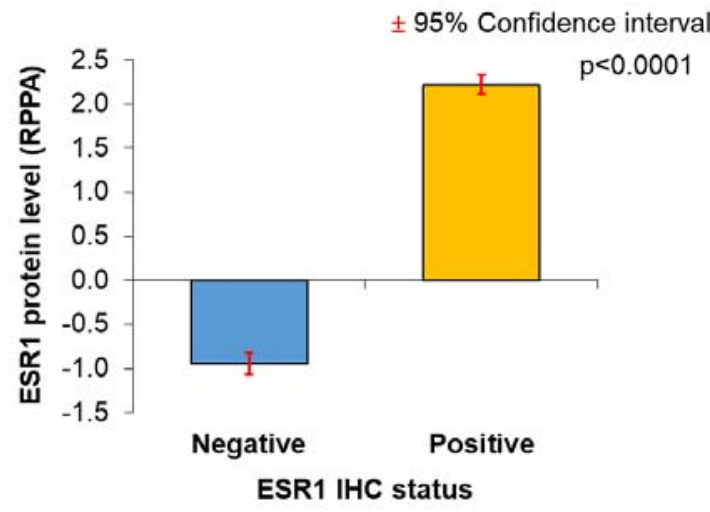

C

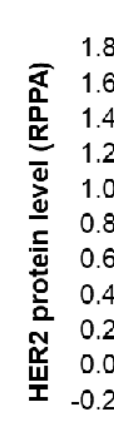

E

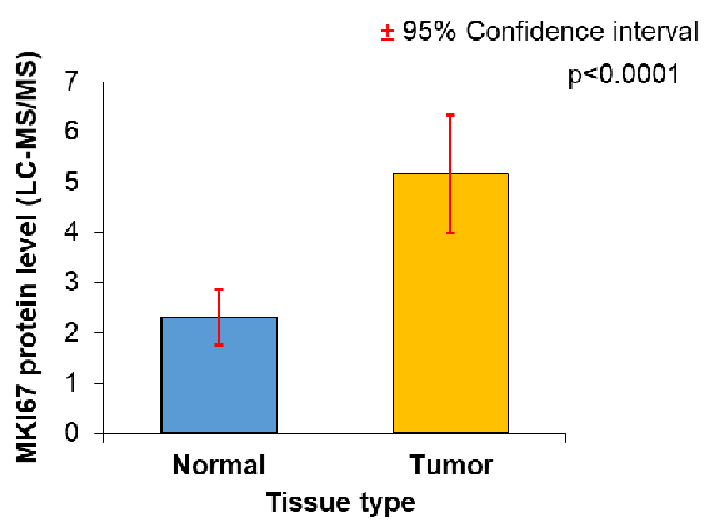

B

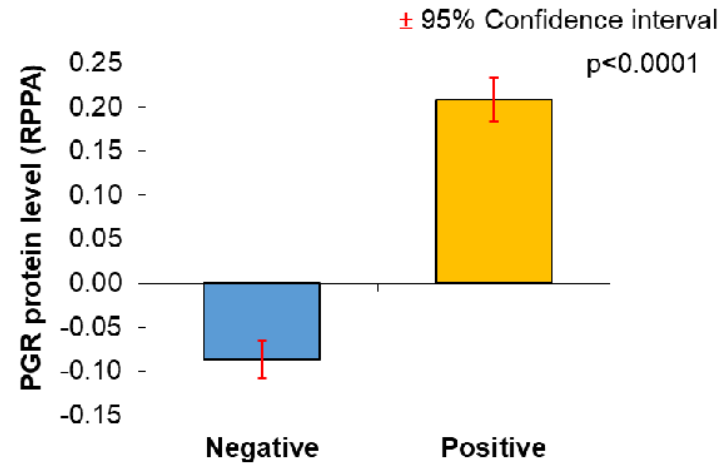

D
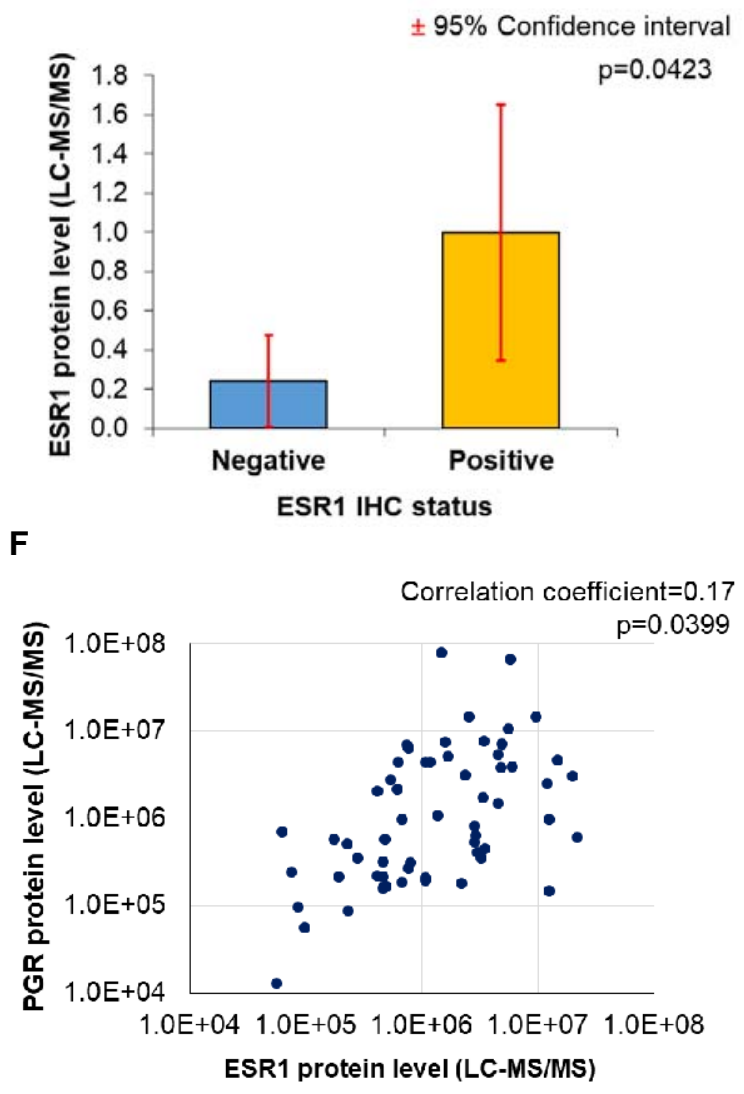
Figure 5. Survival outcome differences in patients with different expression levels of protein biomarkers. Kaplan-Meier plots of overall survival by CDH1 (E-cadherin) (A), apoptosis regulator BCL2 (B), and tyrosine 1248-phosphorylated HER2 (C). Kaplan-Meier plots of relapse-free survival for estrogen receptor 1 (D), progesterone receptor $(\mathbf{E})$ and BCL2 (F) in breast cancer patients. Note the different survival characteristics of the different datasets.

A

CDH1 (P12830)

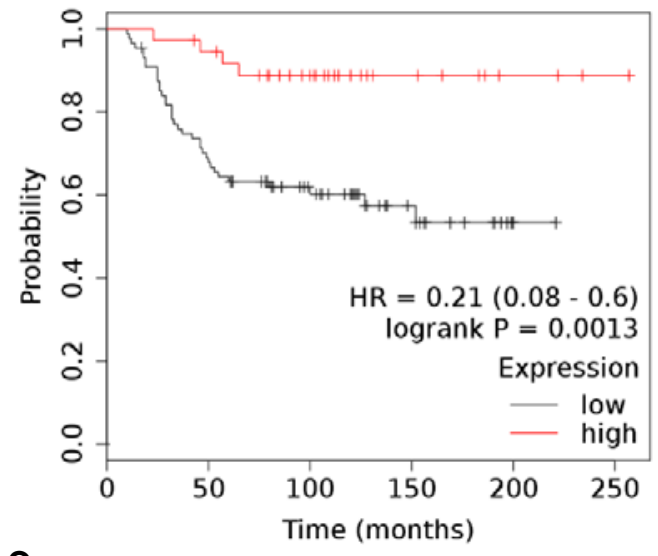

C

ERBB2_pY1248

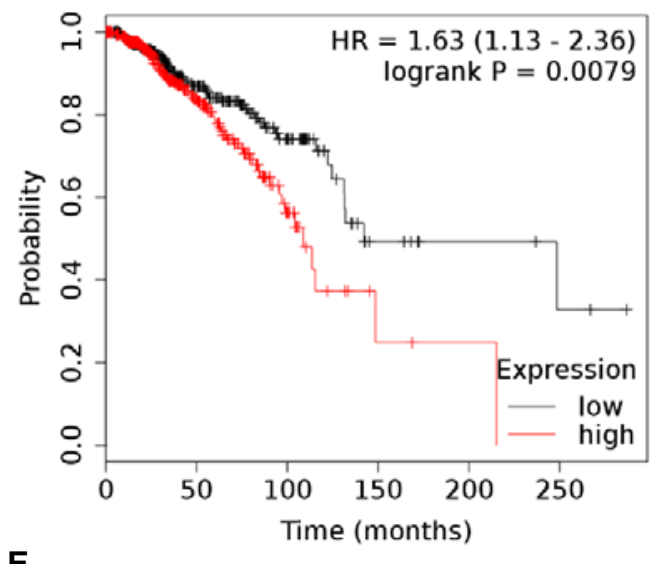

E

PGR (P06401)

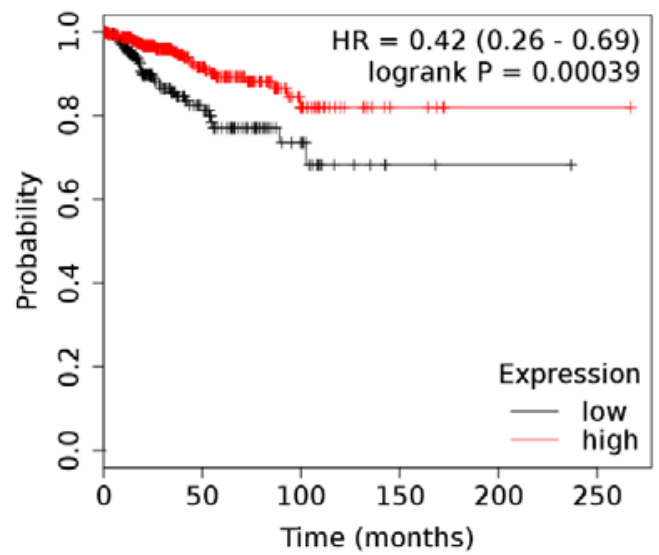

B

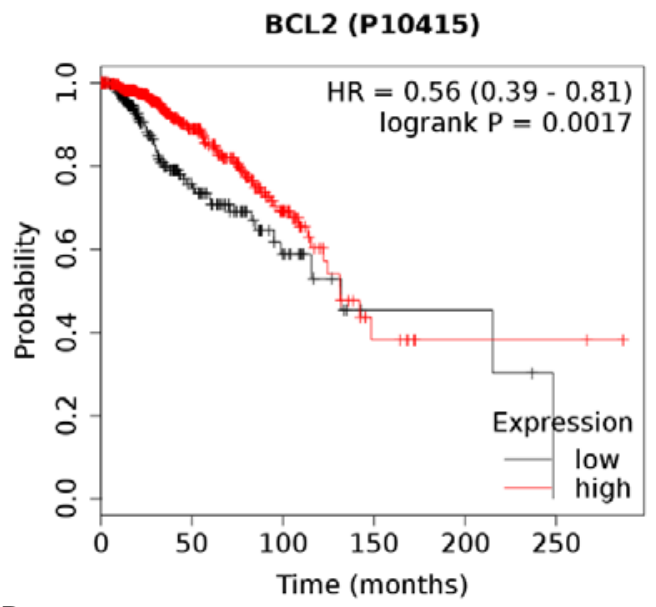

D

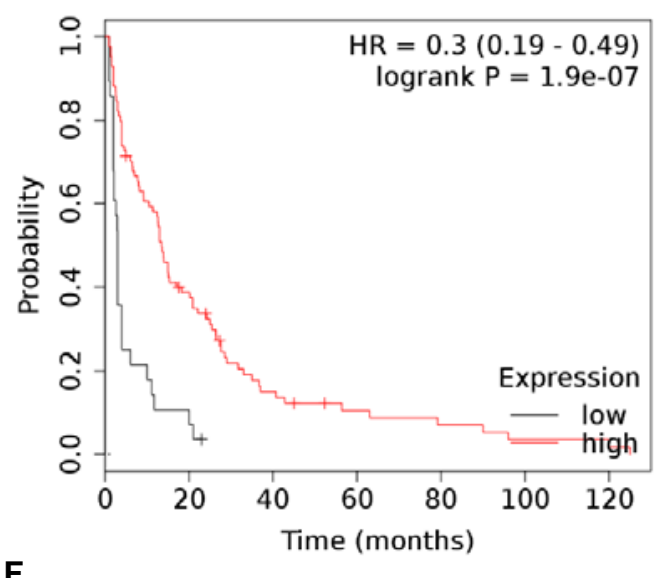

BCL2 (P10415)

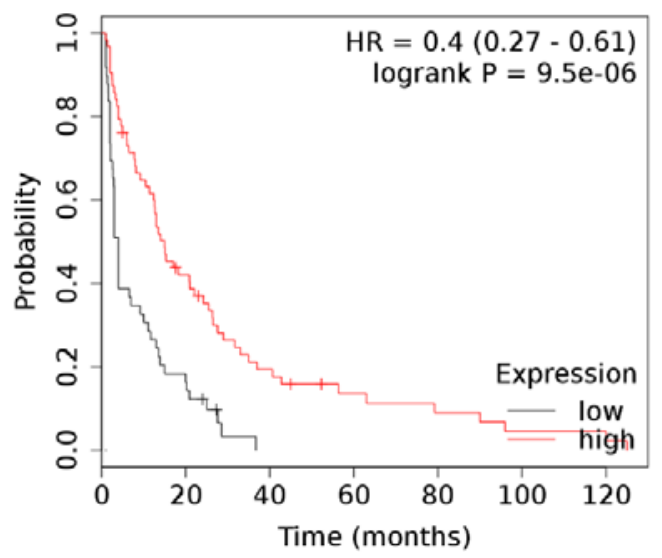




\section{TABLES}

Table 1. Overview of breast cancer proteomic studies.

\begin{tabular}{|c|c|c|c|c|c|c|c|}
\hline Reference & $\begin{array}{l}\text { ProteomeXchange } \\
\text { /CPTAC ID }\end{array}$ & Method used & Survival & $\begin{array}{c}\text { Sample } \\
\mathbf{n}\end{array}$ & Protein n & $\begin{array}{l}\text { Reason for } \\
\text { exclusion }\end{array}$ & Eligible \\
\hline Tang et al. (2018) & PXD005692 & LC-MS/MS & available & 65 & 7141 & - & yes \\
\hline Terunuma et al. (2014) & NA & GC-MS, LC-MS & available & 67 & NA & no protein data & no \\
\hline Mertins et al. (2016) & S039 (CPTAC) & LC-MS/MS & available & 105 & 15369 & only 13 events & no \\
\hline Huang et al. (2017) & S032 (CPTAC) & LC-MS/MS & not available & 24 & 12794 & no survival data & no \\
\hline Waldemarson et al. (2016) & PXD000944 & 2D-DIGE, LC-MS/MS & available & 38 & 14000 & only 38 samples & no \\
\hline Cifani et al. (2015) & PXD000691 & 2D-DIGE, LC-MS/MS & available & 38 & 3681 & only 38 samples & no \\
\hline Liu et al. (2014)a & PXD000260 & nLC-MS/MS & available & 126 & $5000+$ & - & yes \\
\hline Liu et al. (2014)b & PXD000260 & nLC-MS/MS & available & 126 & $5000+$ & - & yes \\
\hline TCGA (2012) & NA & RPPA & available & 348 & 171 & - & yes \\
\hline Bouchal et al. (2015) & PXD000029 & iTRAQ-2DLC-MS/MS & not available & 96 & 4405 & no survival data & no \\
\hline Sjöström et al. (2015) & PXD001685 & LC-MS/MS; LC-SRM & not available & 80 & 778 & no survival data & no \\
\hline De Marchi et al. (2015) & PXD000485 & LC-MS/MS & available & 112 & 3109 & - & yes \\
\hline De Marchi et al. (2016) & PXD002381 & LC-MS/MS & not available & 38 & 3404 & no survival data & no \\
\hline De Marchi et al. (2016) & PXD002381 & LC-MS/MS & not available & 38 & 4 & no survival data & no \\
\hline Pozniak et al. (2016) & PXD000815 & LC-MS/MS & not available & 44 & 10124 & no survival data & no \\
\hline Pedersen et al. (2017) & PXD005544 & TMT-HILIC; LC-MS/MS & not available & 34 & 4163 & no survival data & no \\
\hline Zagorec et al. (2018) & PXD008012 & Ti(IV)-IMAC; LC-MS/MS & not available & 34 & $9000+$ & no survival data & no \\
\hline Tyanova et al. (2016) & PXD002619 & LC-MS/MS & not available & 40 & 10135 & no survival data & no \\
\hline Jiang et al. (2015) & PXD002208 & LC-MS/MS & not available & 53 & 115 & no survival data & no \\
\hline Haukaas et al. (2015) & NA & RPPA & not available & 191 & 150 & no survival data & no \\
\hline Ternette et al. (2018) & PXD009738 & nUPLC $\square \mathrm{MS} / \mathrm{MS}$ & not available & 11 & 6275 & no survival data & no \\
\hline Chen et al. (2018) & PXD007217 & LC-MS/MS & not available & 10 & 388 & no survival data & no \\
\hline Naba et al. (2017) & PXD005554 & LC-MS/MS & not available & 4 & 1000 & no survival data & no \\
\hline Gajbhiye et al. (2017) & PXD006441 & iTRAQ-SCX; LC-MS/MS & not available & 76 & 365 & no survival data & no \\
\hline Chen et al. (2018) & PXD007572 & LC-MS/MS & not available & 56 & 556 & no survival data & no \\
\hline Chen et al. (2017) & PXD005214 & LC-MS/MS & not available & 36 & 2413 & no survival data & no \\
\hline Lobo et al. (2017) & PXD003106 & LC/MS-MS & not available & 40 & 4175 & no survival data & no \\
\hline Braakman et al. (2017) & PXD003632 & nLC/MS-MS & not available & 38 & 2995 & no survival data & no \\
\hline Muraoka et al. 2013 & PXD000066 & nLC-MS/MS & not available & 18 & 7092 & no survival data & no \\
\hline Jordan et al. (2016) & PXD003322 & SPS-based MS3 & not available & 3 & $6300+$ & no survival data & no \\
\hline
\end{tabular}


Table 2. Detailed clinical features of the four protein datasets eligible for this analysis.

\begin{tabular}{|c|c|c|c|c|c|c|c|c|c|c|c|c|c|c|c|c|c|}
\hline $\begin{array}{c}\text { Dataset } \\
\text { (Reference) }\end{array}$ & $\begin{array}{l}\text { Platform } \\
\text { (Company) }\end{array}$ & Technology & $\begin{array}{c}\text { Sample } \\
\text { size }\end{array}$ & $\begin{array}{l}\text { Median } \\
\text { follow-up } \\
\text { (OS, } \\
\text { months) }\end{array}$ & $\begin{array}{l}\text { Progression } \\
\text { events } \\
\text { (OS) }\end{array}$ & $\begin{array}{l}\text { Median } \\
\text { follow-up } \\
\text { (RFS, } \\
\text { months) }\end{array}$ & $\begin{array}{l}\text { Progression } \\
\text { events } \\
\text { (RFS) }\end{array}$ & $\begin{array}{c}\text { ESR1+ } \\
(*)\end{array}$ & $\begin{array}{c}\text { PGR+ } \\
(*)\end{array}$ & $\begin{array}{c}\mathrm{HER} 2+ \\
(*)\end{array}$ & $\begin{array}{c}\text { Stage } \\
(1 / 2 / 3 / 4)\end{array}$ & $\begin{array}{l}\text { Grade } \\
(1 / 2 / 3)\end{array}$ & $\begin{array}{l}\text { Lymph- } \\
\text { node } \\
\text { positive }\end{array}$ & Age & $\begin{array}{c}\text { Radiation } \\
\text { therapy }\end{array}$ & $\begin{array}{c}\text { Hormone } \\
\text { therapy }\end{array}$ & $\begin{array}{l}\text { Chemo- } \\
\text { therapy }\end{array}$ \\
\hline $\begin{array}{l}\text { TCGA- } \\
\text { RPPA } \\
(9,38) \\
\end{array}$ & $\begin{array}{l}2470 \text { Arrayer } \\
\text { (Quanterix) }\end{array}$ & RPPA & 873 & 27.6 & 121 & 25.3 & 64 & 627 & 532 & 133 & $\begin{array}{c}128 / 505 / \\
207 / 18\end{array}$ & - & 452 & $58.2 \pm 13.3$ & 53 & 422 & 488 \\
\hline $\begin{array}{l}\text { Liu } 2014 \\
\quad(19)\end{array}$ & $\begin{array}{l}\text { LTQ-Orbitrap- } \\
\text { XL MS system } \\
\text { (ThermoElectron) }\end{array}$ & LC-MS/MS & 126 & 96.5 & 40 & 85.5 & 50 & 0 & 0 & 0 & - & $2 / 16 / 87$ & 0 & $53.9 \pm 13.8$ & - & 0 & 0 \\
\hline $\begin{array}{l}\text { DeMarchi } \\
2015 \\
(20)\end{array}$ & $\begin{array}{l}\text { LTQ-Orbitrap- } \\
\text { XL MS system } \\
\text { (ThermoElectron) }\end{array}$ & LC-MS/MS & 112 & - & - & 9.6 & 105 & 112 & - & - & - & - & 104 & $61.1 \pm 11.2$ & - & 112 & - \\
\hline $\begin{array}{l}\text { Tang } 2018 \\
\text { (21) }\end{array}$ & $\begin{array}{l}\text { LTQ MS system } \\
\text { (Thermo Fisher } \\
\text { Scientific) }\end{array}$ & LC-MS/MS & 118 & 50.0 & 30 & - & - & 32 & - & - & $6 / 46 / 13 / 0$ & $8 / 19 / 28$ & 27 & $54.5 \pm 15.7$ & - & - & - \\
\hline
\end{tabular}

OS: overall survival, RFS: relapse-free survival

*ER, PGR, HER2 receptor status was identified using both gene expression and immunohistochemistry data in each cohort. 
Table 3. Protein markers with validated prognostic value in breast cancer when assessing the correlation between expression level and overall survival (A) and relapse-free survival (B). Bold: significant at $p<0.05$.

A) Overall Survival

\begin{tabular}{|c|c|c|c|c|c|c|c|c|c|c|c|c|c|c|}
\hline \multicolumn{3}{|l|}{ A) Overall Survival } & \multicolumn{4}{|c|}{ TCGA-RPPA } & \multicolumn{4}{|c|}{ Liu 2014} & \multicolumn{4}{|c|}{ Tang 2018} \\
\hline Protein marker & Symbol & Uniprot ID & $\mathrm{n}$ & HR & $95 \% \mathrm{CI}$ & p-value & $\mathrm{n}$ & HR & $95 \% \mathrm{CI}$ & $\mathrm{p}$-value & $\mathrm{n}$ & HR & $95 \% \mathrm{CI}$ & $\mathrm{p}$-value \\
\hline Estrogen receptor & ESR1 & $\mathrm{P} 03372$ & 733 & 0.82 & $0.55-1.21$ & 0.31 & - & - & - & - & 65 & 1.53 & $0.72-3.26$ & 0.27 \\
\hline Progesterone receptor & PGR & P06401 & 873 & 1.27 & $0.85-1.89$ & 0.24 & - & - & - & - & 65 & 2.23 & $1.01-4.94$ & 0.042 \\
\hline \multirow[t]{2}{*}{ Human epidermal growth factor receptor 2} & HER2 & $\mathrm{P} 04626$ & 836 & 1.32 & $0.9-1.95$ & 0.16 & - & - & - & - & 65 & 1.37 & $0.64-2.92$ & 0.41 \\
\hline & HER2_pY1248 & & 871 & 1.63 & $1.13-2.36$ & 0.0079 & & & & & & & & \\
\hline Androgen receptor & AR & P10275 & 870 & 1.37 & $0.88-2.14$ & 0.16 & - & - & - & - & 65 & 0.29 & $0.1-0.83$ & 0.014 \\
\hline Apoptosis Regulator, BCL2 & BCL2 & P10415 & 869 & 0.56 & $0.39-0.81$ & 0.0017 & - & - & - & - & - & - & - & - \\
\hline Basal markers, Cytokeratin- 8 & KRT8 & P05787 & - & - & - & - & 125 & 1.86 & $0.99-3.49$ & 0.051 & 65 & 2.16 & $1.03-4.55$ & 0.038 \\
\hline Basal markers, Cytokeratin-18 & KRT18 & $\mathrm{P} 05783$ & - & - & - & - & 126 & 0.35 & $0.14-0.88$ & 0.02 & 65 & 2.35 & 1.11-5.00 & 0.022 \\
\hline Basal markers, Cytokeratin-5 & KRT5 & P13647 & - & - & - & - & 126 & 0.54 & $0.29-1.01$ & 0.05 & 65 & 0.41 & $0.19-0.85$ & 0.014 \\
\hline Basal markers, Cytokeratin-6A & KRT6A & $\mathrm{P} 02538$ & - & - & - & - & 121 & 0.63 & $0.3-1.33$ & 0.22 & 65 & 2.17 & $1.02-4.61$ & 0.039 \\
\hline Basal markers, Cytokeratin-6B & KRT6B & $\mathrm{P} 04259$ & - & - & - & - & 115 & 0.46 & $0.23-0.9$ & 0.019 & 65 & 1.89 & $0.91-3.9$ & 0.081 \\
\hline Basal markers, Cytokeratin-17 & KRT17 & Q04695 & - & - & - & - & 126 & 0.49 & $0.26-0.92$ & 0.022 & 65 & 1.59 & $0.61-4.16$ & 0.34 \\
\hline Adhesion marker, E-Cadherin & CDH1 & P12830 & 668 & 1.76 & $1.07-2.89$ & 0.024 & 125 & 0.21 & $0.08-0.6$ & 0.0013 & 65 & 0.58 & $0.28-1.2$ & 0.14 \\
\hline Adhesion markers, Claudin-3 & CLDN3 & O15551 & - & - & - & - & 119 & 0.48 & $0.26-0.91$ & 0.021 & - & - & - & - \\
\hline \multirow[t]{2}{*}{ Transcription factor, Y-box-binding protein 1} & YBX1 & P67809 & 872 & 0.73 & $0.5-1.07$ & 0.11 & - & - & - & - & 65 & 2.07 & $0.99-4.31$ & 0.047 \\
\hline & YBX1_pS102 & & 873 & 1.48 & 1.0-2.17 & 0.046 & - & - & - & - & - & - & - & - \\
\hline Invasion marker, Stromelysin-3 & MMP11 & P24347 & - & - & - & - & - & - & - & - & 65 & 2.09 & $1.0-4.35$ & 0.044 \\
\hline N-myc downstream-regulated gene 1 protein & NDRG1 & Q92597 & - & - & - & - & 126 & 0.66 & $0.34-1.28$ & 0.216 & 65 & 2.24 & $1.07-4.72$ & 0.0288 \\
\hline Catenin beta- 1 & CTNNB1 & P35222 & 873 & 1.38 & $0.84-2.29$ & 0.2031 & 126 & 0.27 & $0.12-0.59$ & 4E-04 & 65 & 1.73 & $0.74-4.07$ & 0.2009 \\
\hline Apolipoprotein D & APOD & $\mathrm{P} 05090$ & - & - & - & - & 126 & 0.56 & $0.29-1.08$ & 0.081 & 65 & 0.35 & $0.12-1.0$ & 0.0411 \\
\hline Poly [ADP-ribose] polymerase 1 & PARP1 & P09874 & 873 & 1.55 & $0.77-3.09$ & 0.2134 & 126 & 0.79 & $0.93-3.48$ & 0.079 & 65 & 2.44 & $1.18-5.05$ & 0.0131 \\
\hline Scavenger receptor cysteine-rich type 1 protein M130 & CD163 & Q86VB7 & - & - & - & - & 126 & 0.74 & $0.35-1.53$ & 0.412 & 65 & 2.43 & $1.17-5.06$ & 0.0138 \\
\hline Fascin & FSCN1 & Q16658 & - & - & - & - & 126 & 0.52 & $0.28-0.98$ & 0.040 & 65 & 2.52 & $1.2-5.26$ & 0.0111 \\
\hline Asporin & ASPN & Q9BXN1 & - & - & - & - & - & - & - & - & 65 & 2.29 & $1.06-4.94$ & 0.0294 \\
\hline RNA-binding protein 3 & RBM3 & P98179 & - & - & - & - & 126 & 0.42 & 0.18-1.01 & 0.045 & 65 & 2.03 & $0.97-4.26$ & 0.056 \\
\hline Glioma-associated oncogene & GLI1 & P08151 & - & - & - & - & - & - & - & - & 65 & 0.43 & 0.18-1 & 0.0427 \\
\hline
\end{tabular}


B) Relapse-free survival

\begin{tabular}{|c|c|c|c|c|c|c|c|c|c|c|c|c|c|c|}
\hline \multicolumn{3}{|l|}{ Relapse-free survival } & \multicolumn{4}{|c|}{ TCGA-RPPA } & \multicolumn{4}{|c|}{ Liu 2014} & \multicolumn{4}{|c|}{ DeMarchi 2015} \\
\hline Protein marker & Symbol & Uniprot ID & $\mathrm{n}$ & HR & $95 \% \mathrm{CI}$ & p-value & $\mathrm{n}$ & $\mathrm{HR}$ & $95 \% \mathrm{CI}$ & p-value & $\mathrm{n}$ & HR & $95 \% \mathrm{CI}$ & $\mathrm{p}$-value \\
\hline Estrogen receptor & ESR1 & P03372 & 623 & 0.64 & $0.36-1.14$ & 0.13 & - & - & - & - & 112 & 0.3 & $0.19-0.49$ & $1.9 e-07$ \\
\hline Progesterone receptor & PGR & P06401 & 750 & 0.42 & $0.26-0.69$ & 0.0004 & - & - & - & - & 112 & 0.61 & $0.41-0.92$ & 0.018 \\
\hline \multirow[t]{2}{*}{ Human epidermal growth factor receptor 2} & HER2 & P04626 & 719 & 1.19 & $0.73-1.96$ & 0.48 & - & - & - & - & 112 & 0.75 & $0.51-1.11$ & 0.15 \\
\hline & HER2_pY1248 & & 748 & 0.68 & $0.39-1.21$ & 0.19 & & & & & & & & \\
\hline Apoptosis Regulator, BCL2 & BCL2 & P10415 & 746 & 0.51 & $0.31-0.84$ & 0.0071 & - & - & - & - & 112 & 0.4 & $0.27-0.61$ & $9.5 \mathrm{e}-06$ \\
\hline Basal markers, Cytokeratin-18 & KRT18 & P05783 & - & - & - & - & 124 & 0.39 & $0.17-0.86$ & 0.016 & - & - & - & - \\
\hline Basal markers, Cytokeratin-5 & KRT5 & P13647 & - & - & - & - & 124 & 0.49 & $0.28-0.85$ & 0.01 & - & - & - & - \\
\hline Basal markers, Cytokeratin-6B & KRT6B & P04259 & - & - & - & - & 113 & 0.43 & 0.23-0.77 & 0.004 & - & - & - & - \\
\hline Basal markers, Cytokeratin-17 & KRT17 & Q04695 & - & - & - & - & 124 & 0.51 & $0.29-0.88$ & 0.014 & - & - & - & - \\
\hline Adhesion marker, E-Cadherin & $\mathrm{CDH} 1$ & P12830 & 578 & 1.83 & $0.93-3.58$ & 0.075 & 123 & 0.35 & 0.16-0.78 & 0.007 & 112 & 0.61 & $0.39-0.95$ & 0.026 \\
\hline Adhesion markers, Claudin-7 & CLDN7 & O95471 & 715 & 1.67 & $1-2.79$ & 0.048 & - & - & - & - & 112 & 0.72 & $0.49-1.06$ & 0.098 \\
\hline Apoptotic marker, Tumorsupressor p53 & TP53 & P04637 & 727 & 1.84 & 1.12-3.02 & 0.014 & - & - & - & - & - & - & - & - \\
\hline Bcl-2-associated athanogene 1 & BAG1 & Q99933 & - & - & - & - & - & - & - & - & 112 & 0.58 & $0.39-0.86$ & 0.0061 \\
\hline Carcinoembryonic antigen-related cell adhesion molecule 5 & CEACAM5 & P06731 & - & - & - & - & - & - & - & - & 112 & 0.66 & 0.43-1.00 & 0.049 \\
\hline $\mathrm{N}$-myc downstream-regulated gene 1 protein & NDRG1 & Q92597 & - & - & - & - & 124 & 0.58 & $0.33-1.03$ & 0.059 & 112 & 0.56 & $0.37-0.87$ & 0.0084 \\
\hline Large neutral amino acids transporter small subunit 1 & SLC7A5 & Q01650 & - & - & - & - & - & - & - & - & 112 & 1.5 & $1.01-2.22$ & 0.0455 \\
\hline Catenin beta- 1 & CTNNB1 & P35222 & 750 & 0.73 & $0.71-1.3$ & 0.2823 & 124 & 0.36 & $0.19-0.7$ & 0.002 & 112 & 0.56 & $0.36-0.85$ & 0.0061 \\
\hline Apolipoprotein D & APOD & P05090 & - & - & - & - & 124 & 0.64 & $0.35-1.15$ & 0.133 & 112 & 0.59 & $0.38-0.91$ & 0.0161 \\
\hline Poly [ADP-ribose] polymerase 1 & PARP1 & P09874 & 750 & 0.46 & $0.17-1.3$ & 0.1341 & 124 & 1.49 & $0.83-2.66$ & 0.176 & 112 & 0.65 & 0.44-0.97 & $\mathbf{0 . 0 3 4 9}$ \\
\hline Carcinoembryonic antigen-related cell adhesion molecule 6 & CEACAM6 & P40199 & - & - & - & - & - & - & - & - & 112 & 0.56 & $0.38-0.84$ & 0.0044 \\
\hline Ras-related protein Rab-27B & RAB27B & O00194 & - & - & - & - & - & - & - & - & 112 & 0.59 & 0.37-0.92 & 0.0183 \\
\hline RNA-binding protein 3 & RBM3 & P98179 & - & - & - & - & 124 & 0.40 & $0.19-0.86$ & 0.016 & 112 & 0.78 & $0.51-1.18$ & 0.2466 \\
\hline GATA-binding factor 3 & GATA3 & P23771 & 750 & 0.61 & $0.37-1.01$ & 0.0544 & - & - & - & - & 112 & 0.49 & $0.32-0.74$ & 0.0007 \\
\hline
\end{tabular}


medRxiv preprint doi: https://doi.org/10.1101/2020.12.03.20242065; this version posted December 4, 2020. The copyright holder for this preprint (which was not certified by peer review) is the author/funder, who has granted medRxiv a license to display the preprint in perpetuity.

It is made available under a CC-BY-NC 4.0 International license .

\section{SUPPLEMENTARY MATERIAL}

Supplemental table 1: Protein list

Supplemental table 2: Protein biomarkers 
